\title{
Existing data sources for clinical epidemiology: Danish registries for studies of medical genetic diseases
}

This article was published in the following Dove Press journal:

Clinical Epidemiology

7 August 2013

Number of times this article has been viewed

\author{
Mary Nguyen-Nielsen' \\ Elisabeth Svensson' \\ Ida Vogel ${ }^{2}$ \\ Vera Ehrenstein' \\ Lone Sunde ${ }^{2}$
}

'Department of Clinical Epidemiology, Aarhus University Hospital, Denmark; ${ }^{2}$ Department of Clinical Genetics, Aarhus University Hospital, Denmark

Correspondence: Mary Nguyen-Nielsen Department of Clinical Epidemiology, Aarhus University Hospital, Olof Palmes Allé 43-45, 8200 Aarhus N, Denmark Tel +4587167607

Fax +4587167215

Email mary.n.nielsen@dce.au.dk

\begin{abstract}
Denmark has an extensive collection of national and regional medical registries. There are many advantages to registry-based research when investigating genetic diseases which, due to their rarity, can be difficult to identify. In this study, we aimed to provide an updated overview of Danish registries for medical genetic conditions and describe how data linkage across registries can be used to collect data on genetic diseases at the individual level and at the family level. We present a list of medical genetic registries in Denmark at the national level, data sources from the departments of clinical genetics and other specialized centers, and project-specific data sources. We also summarize key general registries, such as the Danish National Registry of Patients, the Danish Medical Birth Registry, and the Civil Registration System, which are renowned for their comprehensive and high quality data, and are useful supplemental data sources for genetic epidemiology research. We describe the potential for data linkage across multiple registries, which allows for access to medical histories with follow-up time spanning birth to death. Finally, we provide a brief introduction to the Danish epidemiological research setting and legalities related to data access. The Danish collection of medical registries is a valuable resource for genetic epidemiology research.
\end{abstract}

Keywords: epidemiology, registry-based research, genetic disorders

\section{Introduction}

In many countries, identifying persons with a genetic condition in the background population can be difficult due to the rarity of genetic diseases, diagnostic challenges, and lack of systematic registration. The task can be akin to finding a "needle in a haystack," often requiring multidisciplinary and cross-national efforts. Denmark, however, has an extensive collection of medical and administrative registries and databases that provide a unique opportunity to collect patient data at the individual level routinely, in some cases at the family level, and to carry out reliable kinship tracking. ${ }^{1,2}$ A registry-based research approach has many advantages, particularly when investigating inheritable conditions. Cohorts can be assembled relatively quickly and relevant medical histories can be obtained by linking data from multiple data sources.

In 1982, Broeng-Nielsen et al compiled a bibliography entitled "Danish Family Studies of Medical Genetic Disorders 1927-1980". ${ }^{3}$ In this work, 672 bibliographic references covering 344 genetic disorders were identified, along with seven medical registries (which were listed, without providing details). To our knowledge, no updated compilation of Danish genetic data sources has been made since then. Therefore, we set out to provide an updated overview of Danish registries for medical 
genetic conditions; describe how data linkage across registries can be used to collect data on genetic diseases at the individual level and at the family level; and provide a brief introduction to the Danish epidemiological research setting and legalities related to data access.

\section{Materials and methods \\ Danish health care infrastructure}

The Danish health care system provides equal access to medical care for all residents. Approximately $85 \%$ of Danish health care is tax-funded, with the remaining $15 \%$ paid outof-pocket. ${ }^{4}$ General practitioners are gatekeepers, providing referrals to specialists when appropriate, and the majority of specialist care is hospital-based. Contacts to the primary (ie, general practitioners) and secondary (ie, hospitals) health care sectors are registered, as are prescriptions redeemed at outpatient pharmacies. ${ }^{4}$ The treating physician/department is responsible for reporting data to the relevant registry, and reporting primarily occurs electronically and automatically. Funding by the national government for services rendered is based on the registration and coding of services provided at each health care site. Therefore, the Danish health care system is conducive to completeness of registration. Each person in Denmark is issued a unique personal (CPR) identification number upon birth or immigration. The CPR number encodes, amongst other things, date of birth and gender, and is the means by which information on a given individual can be merged unambiguously from multiple data sources. ${ }^{5}$ Thus, the Danish health care system has a long tradition of high quality longitudinal registry data, in a setting of universal health care access.

\section{Identification of medical registries for genetic diseases}

We sent inquiries for medical data sources on genetic diseases with the potential to be used in registry-based research to relevant registry administrators, hospital departments (eg, departments of clinical genetics, pediatrics, and dermatology), specialized medical centers (eg, Center for Rare Diseases [Center for Sjældne Sygdomme], Clinic for Rare Handicaps [Klinik for Sjældne Handicaps], and Centre for Oral Health in Rare Diseases [Odontologisk Videncenter]), governmental agencies (eg, the Danish Health and Medicines Authority [Sundhedsstyrelsen], and the Danish Data Protection Agency [Datatilsynet]), and performed Internetbased searches. Once identified, we contacted key registry administrators for updated information and verification of the status of a given registry. Information on biobanks was considered beyond the scope of this work, and is therefore not included (with the exception of the Danish Newborn Screening Biobank and Registry, ${ }^{6}$ which can be considered as both a registry and a biobank).

\section{Data sources for genetic epidemiology research}

We identified 29 potential medical data sources for genetic research and a further 12 hospital departments and specialized centers. The data sources are summarized in Tables 1-4 and categorized into four main groups: national registries (Table 1); data from hospital departments and centers (Table 2); project-specific data sources established in relation to various research projects, eg, $\mathrm{PhD}$ dissertations (Table 3); and supplemental registries for data linkage and collection of medical histories (Table 4).

In the following section, we list examples of well established genetic and supplemental data sources. Despite our best efforts to achieve completeness, we recognize that this may not be an exhaustive list detailing all existing genetic registries in Denmark.

\section{National registries (Table I) Danish cytogenetic central register}

The Danish Cytogenetic Central Register is a nationwide registry of all karyotypes done prenatally and postnatally since the advent of cytogenetic analysis in the early 1960s. The register holds over 300,000 total registrations with approximately 10,000 new registrations each year. ${ }^{7,8}$ The register also contains information on specific genetic diseases, such as Fragile-X, Prader-Willi, and Angelman syndromes. The primary purpose of this register is to gather prenatal and postnatal data for the study of trends in prenatal diagnostics and chromosomal aberrations, including type and prevalence. The Danish Cytogenetic Central Register has been an important data source for the study of monosomy $\mathrm{X}$ and trisomy 13,18 , and 21 , in addition to other research projects. ${ }^{9}, 10$

\section{Genetic cancer registries}

The Hereditary Nonpolyposis Colorectal Cancer Register and Hereditary Breast and Ovarian Cancer Registry are two examples of national registries for inheritable cancer risk. Data registration occurs systematically and nationwide. The Hereditary Nonpolyposis Colorectal Cancer Register ${ }^{11,12}$ was established in 1991, with nationwide data collection since 1995. The Hereditary Breast and Ovarian Cancer Registry was established in 1999. Both registers collect 
data on index cancer cases and relatives at risk (eg, referred on to specialist evaluation because of an accumulation of relatives with specific cancers or very young individuals with cancer). The Hereditary Breast and Ovarian Cancer Registry operates under the auspices of the Danish Breast Cancer Cooperative Group and is part of an umbrella clinical database that was established by the Danish Breast Cancer Cooperative Group in the late 1970s. ${ }^{13}$ Numerous publications have arisen from data stemming from both registries. ${ }^{13,14}$

The Danish Cancer Registry (DCR) has recorded solid tumor cancers in Denmark since 1943, with mandatory reporting since $1987 .{ }^{15-17}$ Sites of malignancy are recorded using International Classification of Diseases diagnosis codes, 10th revision (ICD-10). ${ }^{18}$ The DCR is an important data source for identifying heritable cancer risk. Former disease-specific registries, such as the Retinoblastoma Registry, can presently be found as data merged within the DCR. ${ }^{19}$

\section{Registries for specific genetic diseases}

The Danish Huntington's Register is an example of a nationwide, disease-specific registry that has been tracking Danish patients with Huntington's chorea since 1940 via pedigrees and genetic testing. ${ }^{20}$ This register was converted to electronic records in 1980 and has over 12,000 registrations of subjects either known to have Huntington's disease or at risk of developing the disease. Both living and deceased individuals are registered..$^{21}$ This registry has been used to study crime among patients with Huntington's disease as well as other research topics. ${ }^{21,22}$ The Danish Huntington's Register also contributes data to the European Huntington's Disease Network Registry. ${ }^{23}$

The Danish Cystic Fibrosis Patient Registry is another example of a well established, disease-specific registry. ${ }^{24}$ It was established in 2001 and had 451 cystic fibrosis cases registered as of December 31, 2009 (ie, all patients with cystic fibrosis in Denmark, both living and deceased). This registry contributes data to the European Cystic Fibrosis Society Patient Registry ${ }^{25}$ and serves as an important data source for ongoing research. ${ }^{26}$

The Danish Family Archive for Genetic Eye Diseases (Dansk Familiearkiv for Arvelige Øjensygdomme) started around 1985 as a nonelectronic register at the National Eye Clinic (Statens Øjenklinik). It is a nationwide umbrella registry of heritable eye diseases, with over 100 different conditions represented, including retinitis pigmentosa, which has its own subregistry (see Table 1). To date, there are over 100 published studies based on data from this registry, including studies on $\mathrm{X}$-linked ocular albinism and retinitis pigmentosa. ${ }^{27,28}$

\section{Neonatal registries}

The National Registry of Congenital Malformations registers all congenital malformations detected during the first year of life, with data registration from 1983 to $1995 .{ }^{29}$ During this period, all diagnosing physicians were required to register and illustrate (by free drawing) all structural congenital abnormalities (eg, congenital heart valve defects, cleft lip, and/or cleft palate), making these registrations very detailed and specific. Despite this, the registry is unfortunately known to have incomplete data. ${ }^{30}$ From 1996 and onwards, congenital malformations have been electronically reported to the Danish National Registry of Patients (DNRP) ${ }^{7}$ and can be identified using the corresponding ICD-10 codes. ${ }^{18}$ Recent epidemiological studies have accessed data on congenital malformations directly from the DNRP. ${ }^{31}$ Since not all birth defects are due to chromosomal abnormalities, this particular neonatal registry is unique in that it provides data on structural congenital abnormalities. Other relevant registries with perinatal/neonatal data include the Danish Medical Birth Registry $^{32}$ (see section on data linkage), the National Fetal Medicine Database, ${ }^{33}$ and the Danish Newborn Screening Biobank and Registry ${ }^{6}$ (see Table 4).

\section{Data from the Danish departments of clinical genetics (Table 2)}

In Denmark, the vast majority of genetic investigations and genetic counseling are undertaken at hospital departments of clinical genetics, located in the cities of Aalborg, Aarhus, Odense, Vejle, and Copenhagen. These departments store data on patients and families seen in the genetic outpatient clinics and/or investigated at clinical genetics laboratories. For instance, as of 2012, there were over 20,000 patients registered at the Department of Clinical Genetics, Aarhus University Hospital alone.

The departments of clinical genetics in Aarhus, Odense, and Aalborg currently use the Langtved database ${ }^{34}$ to register and store patient data, primarily for genetic counseling. The Langtved database uses ICD-10 codes to encode broad categories of familial diseases, internal conventions determined by senior geneticists, and the internationally used McKusick codes. ${ }^{35}$ Data are also registered in pedigrees (eg, the Cyrilic database, used from 1993 to 2013, and the PASS Clinical ${ }^{\circledR}$ genetic database ${ }^{36}$ used from 2013). Table 2 shows further relevant departments and centers in Denmark. 


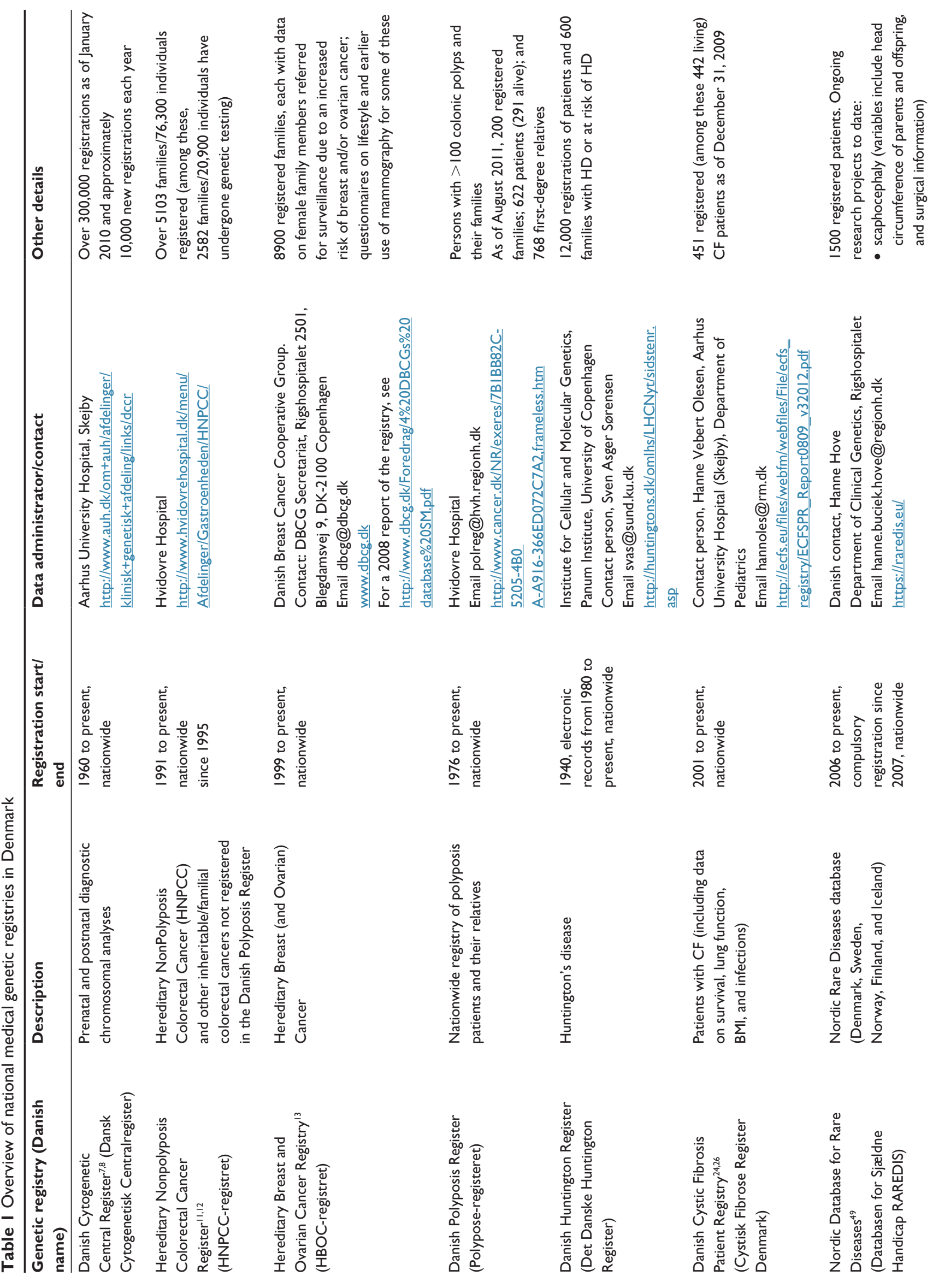



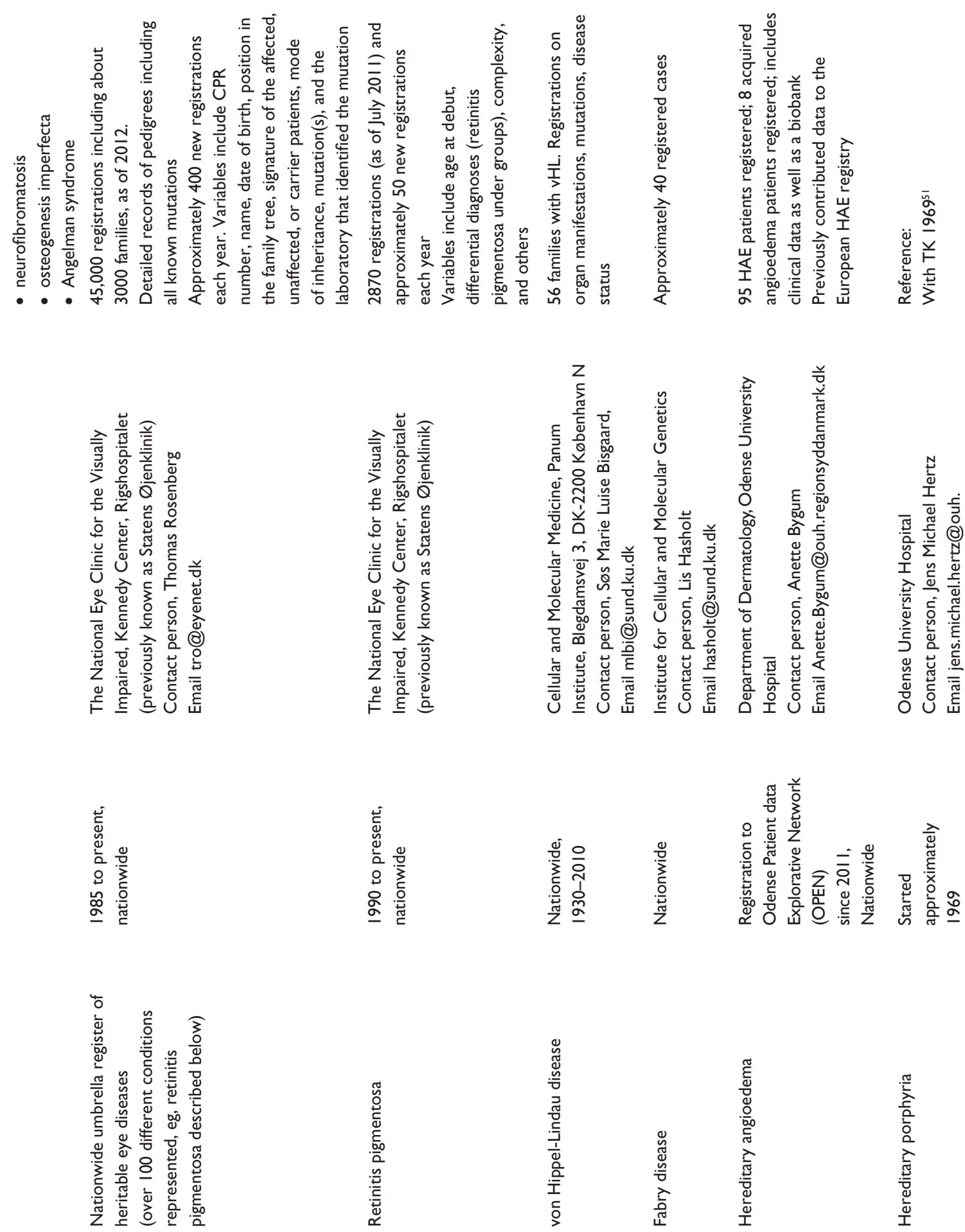

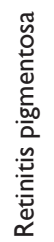
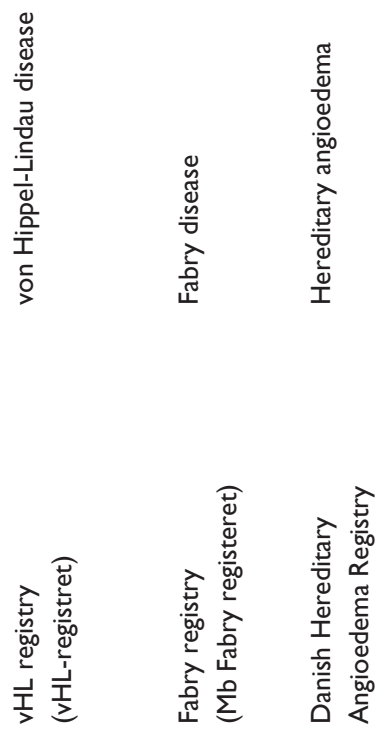

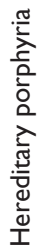
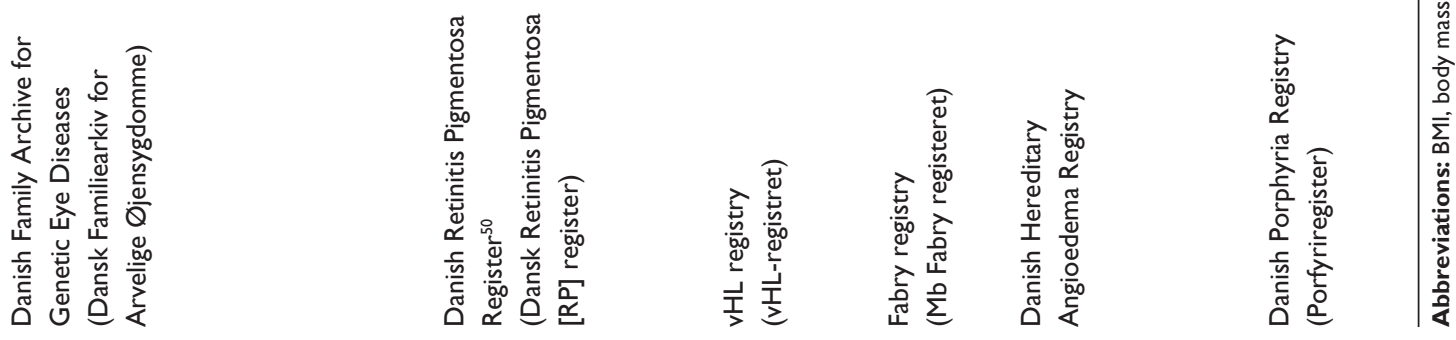


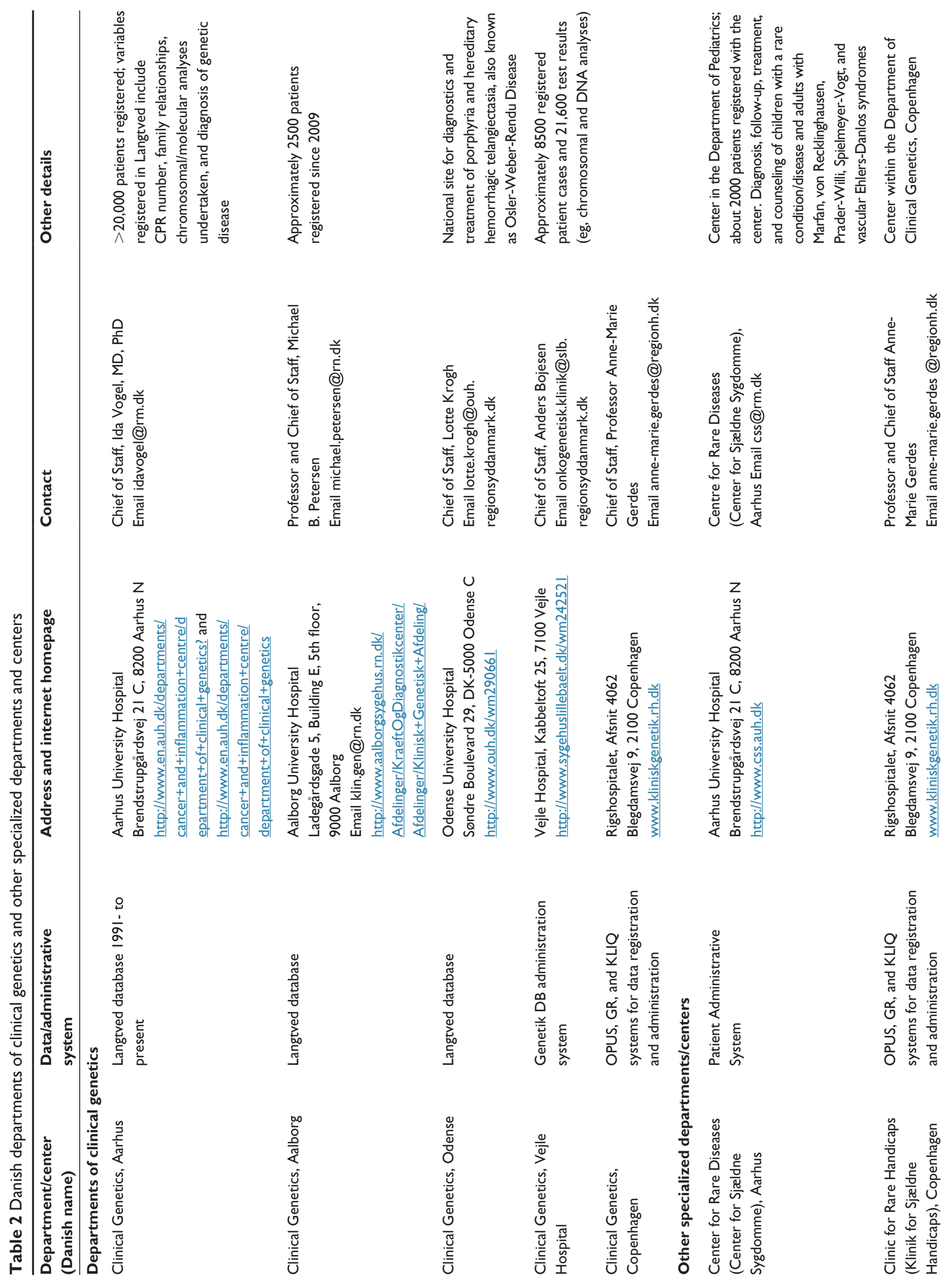



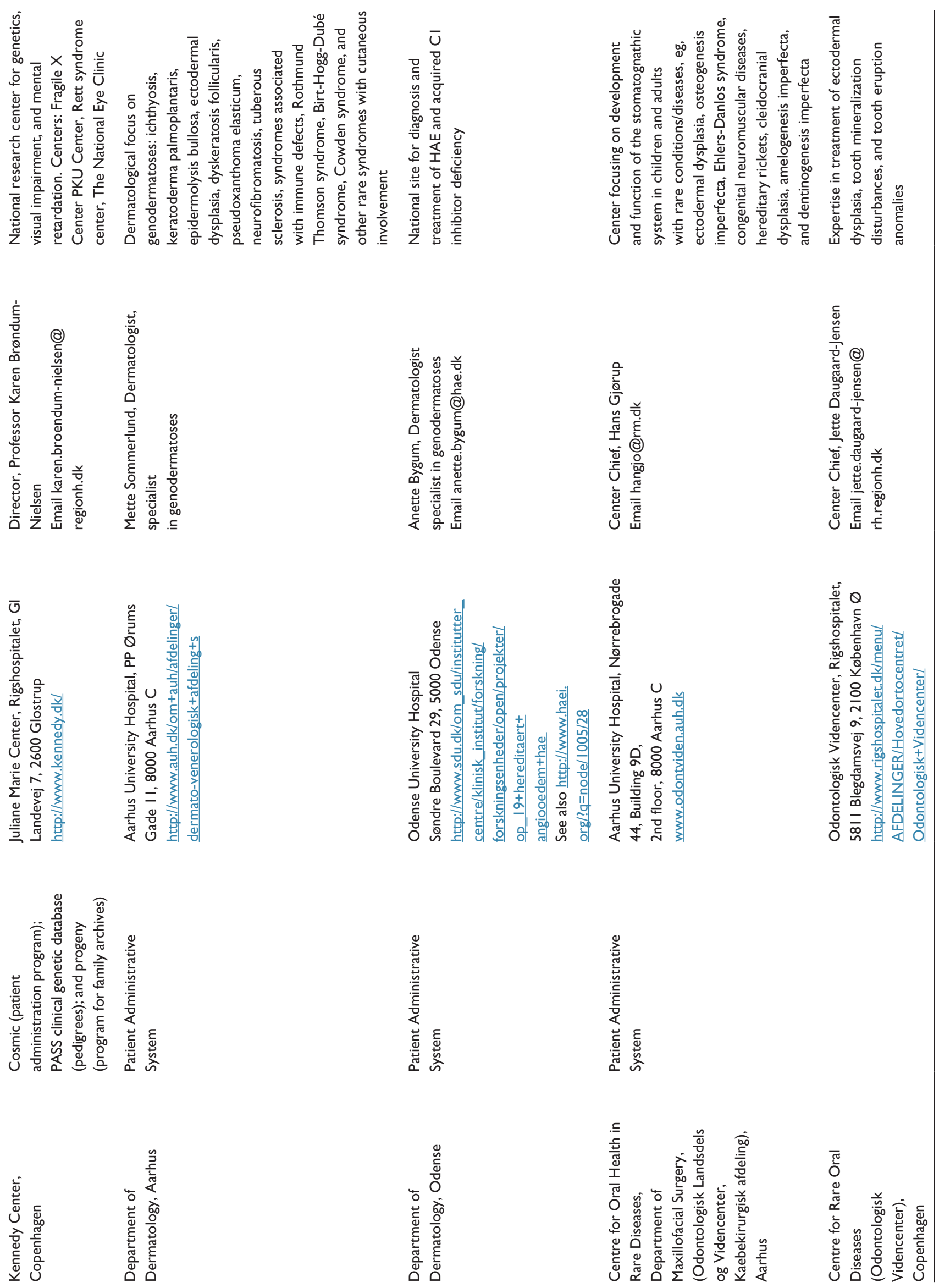


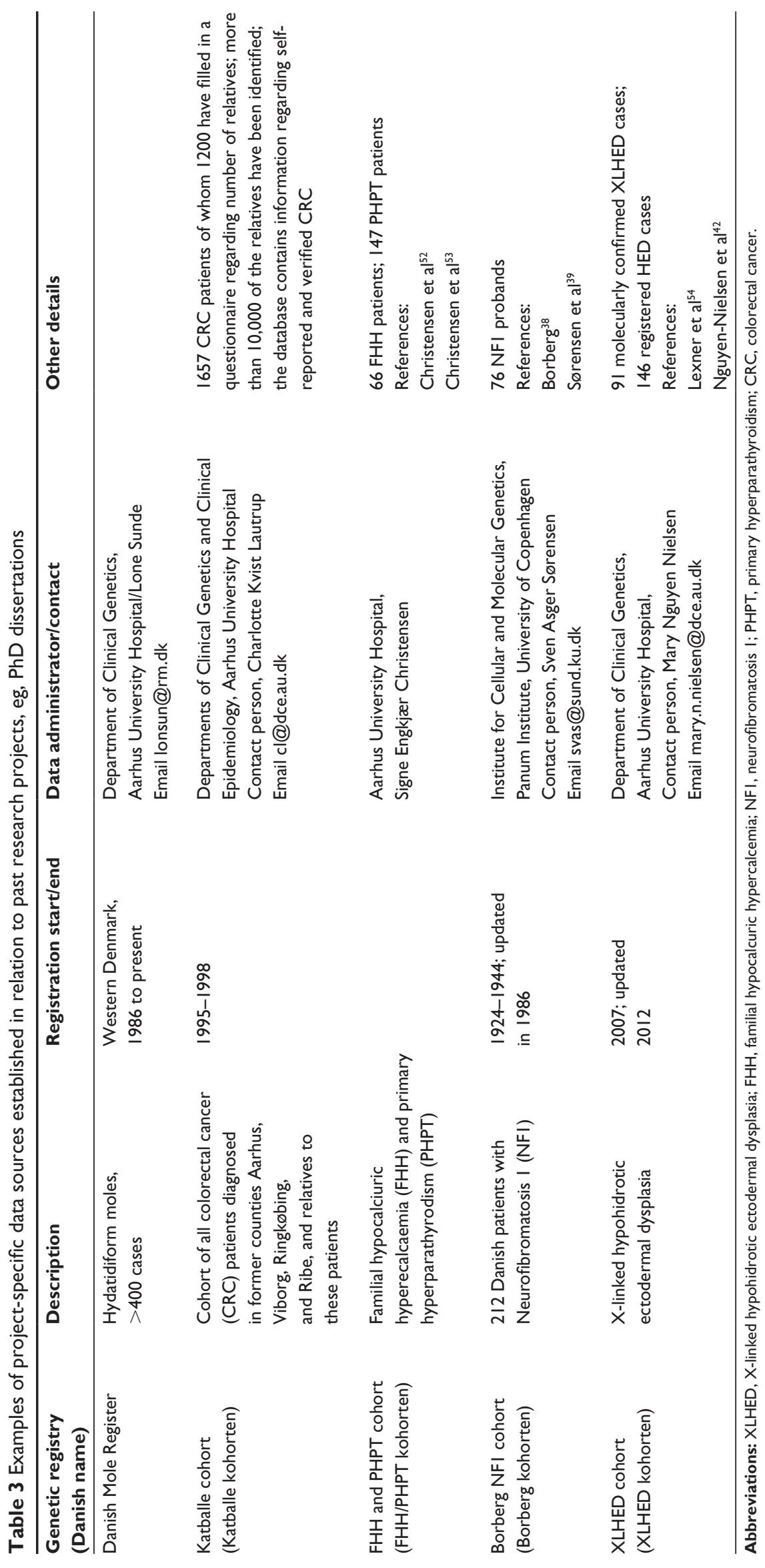




\section{Project-specific data sources (Table 3)}

Data from completed $\mathrm{PhD}$ dissertations or clinical studies are other important data sources. It is here that many hours of "field work" finding and meeting patients with rare genetic diseases have taken place, and from which future studies can expand upon (see Table 3). The annotated bibliography published by Broeng-Nielsen et al is a historical list of over 600 genetic studies conducted up until 1980. The Danish National Research Database (www.forskningsdatabasen.dk) contains a public list of Danish research projects from which past $\mathrm{PhD}$ dissertations can be queried, as well as conference publications and scientific articles. ${ }^{37}$ The established projects can be a springboard for future studies, with the advantage of having pre-established patient cohorts.

In 1980, Broeng-Nielsen et al warned about the potential loss of valuable pedigree data upon retirement or death of the principal investigators listed in the bibliography. ${ }^{3}$ Data from more than half of the studies listed in this annotated bibliography were stored by individual investigators, many of them close to retirement age. Therefore, the establishment and maintenance of numerous genetic registries over recent decades has had an important role in the conservation of medical genetic data. Owing to this, several Danish genetic registries contain pedigrees and cohorts that span several generations. In the following section, we illustrate projectspecific data sources with two examples, ie, the neurofibromatosis 1 cohort and the X-linked hypohidrotic ectodermal dysplasia cohort.

\section{Neurofibromatosis I cohort}

Neurofibromatosis 1, also known as von Recklinghausen disease, is an autosomal dominant condition with varying clinical manifestations, including characteristic café-au-lait spots in the skin and neurofibromas. The Borberg cohort of patients with neurofibromatosis 1 was established in $1940^{38}$ and reinvestigated in a follow-up study 46 years later. Sørensen et $\mathrm{al}^{39}$ revisited this established cohort and linked to data from the DCR to follow patients for the development of malignant neoplasms after diagnosis of neurofibromatosis 1 . The registry-based approach was also used in the same study to investigate risk factors and survival.

\section{X-linked hypohidrotic ectodermal dysplasia cohort}

XLHED is a monogenetic condition affecting the skin, hair, and teeth. Using CPR numbers, data were collected from the relevant clinical departments, the Statens Centrale
Odontologiske Register (SCOR) database, ${ }^{40}$ the DNRP, and the Civil Registration System. ${ }^{41}$ A cohort of 1224 persons was assembled, and population-based prevalence estimates and frequency of clinical features were calculated. ${ }^{42}$ Patients with X-linked hypohidrotic ectodermal dysplasia (XLHED) (ie, gene tested and/or clinically diagnosed) were identified by inquiry at the relevant departments. The DNRP and SCOR database were then searched to identify additional cases by finding patients with a clinical diagnosis of XLHED and cardinal features associated with the condition (eg, skin, hair, and teeth disorders). The cohort can be expanded by linking to the Danish Medical Birth Registry to identify additional obligate carriers. This cohort can be used for future studies of disease incidence, mortality, and other outcomes.

\section{Supplemental registries for data linkage and the collection of medical histories (Table 4)}

The DNRP, ${ }^{43}$ the Civil Registration System, ${ }^{41}$ the DCR, ${ }^{15}$ the Danish Medical Birth Registry, ${ }^{32}$ and the National Pathology Registry ${ }^{44}$ are examples of major nationwide medical and administrative registries that can be used as supplemental data sources in epidemiologic studies of genetic diseases (Table 4).

The DNRP is a nationwide patient registry of diagnoses, procedures, and treatments from all hospitals in Denmark. Established in 1977, the DNRP uses the International Classification of Diseases diagnosis codes. Prior to 1994, the ICD-8 was used; from 1994 and onwards, the ICD-10 version has been used. Patients can be identified by the specific ICD diagnosis code, by alternative identification methods (eg, predefined clinical algorithms based on a constellation of diagnoses and/or procedures), or in combination with data on medication use from the Danish Prescription Registry. ${ }^{45}$ Further, when linked to the DNRP for inhospital treatment data and/or to the Danish Prescription Registry for redeemed prescriptions, a genetic cohort can potentially be used in comparative effectiveness research to provide evidence on the effectiveness, benefits, and harms of different treatments. One limitation of the DNRP with regard to identifying patients with genetic conditions is that some genetic disorders are not registered with a specific ICD-10 code, but rather with a general ICD-10 code, eg, DZ80.0 (family history of gastrointestinal cancer) or the unspecific ICD-10 Z848 (family history of other specified conditions). This registration practice is used by geneticists to protect patient privacy. Further, family history is likely to be under-reported in the DNRP. Therefore, it is crucial that clinical geneticists or other 


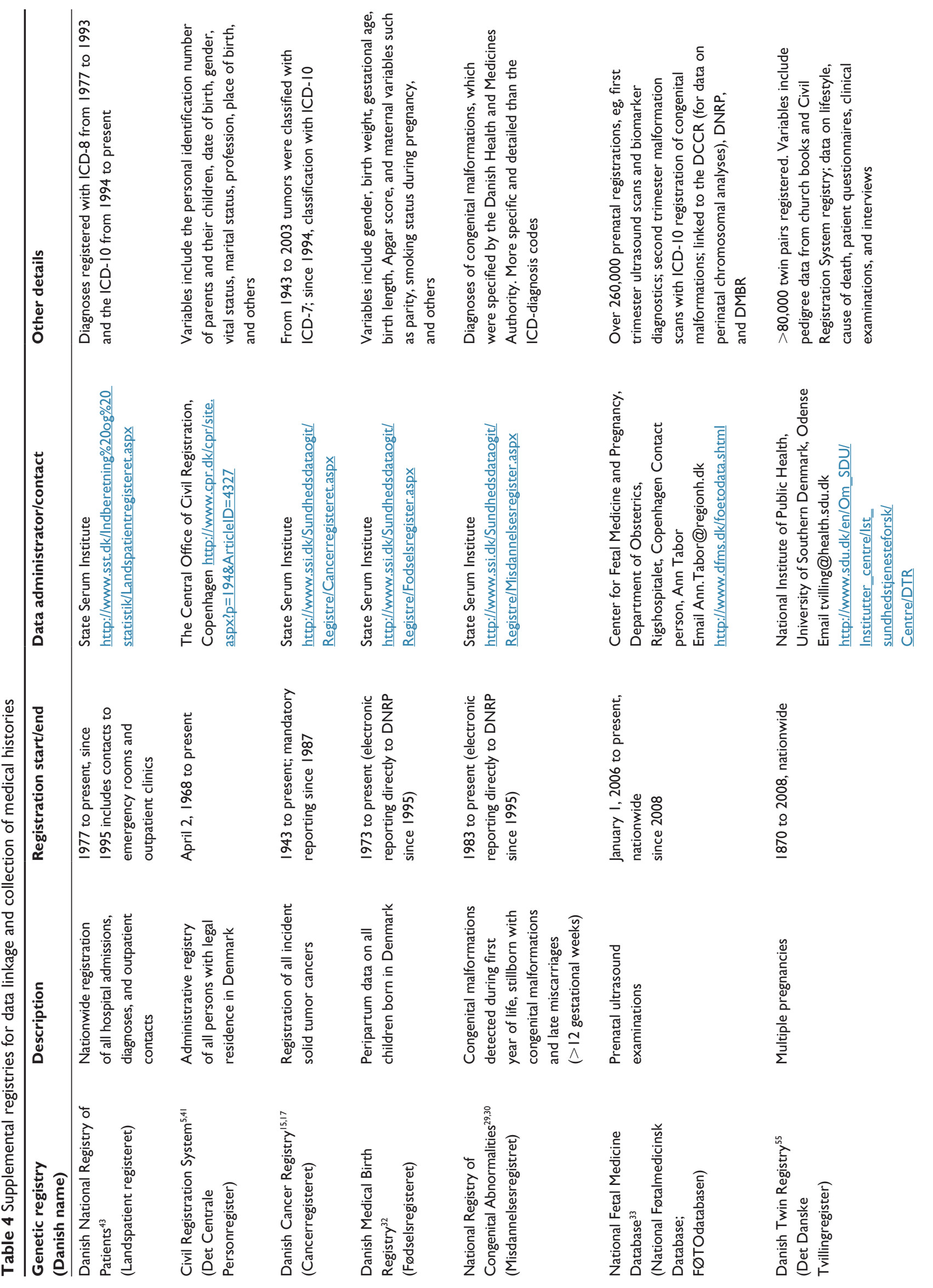



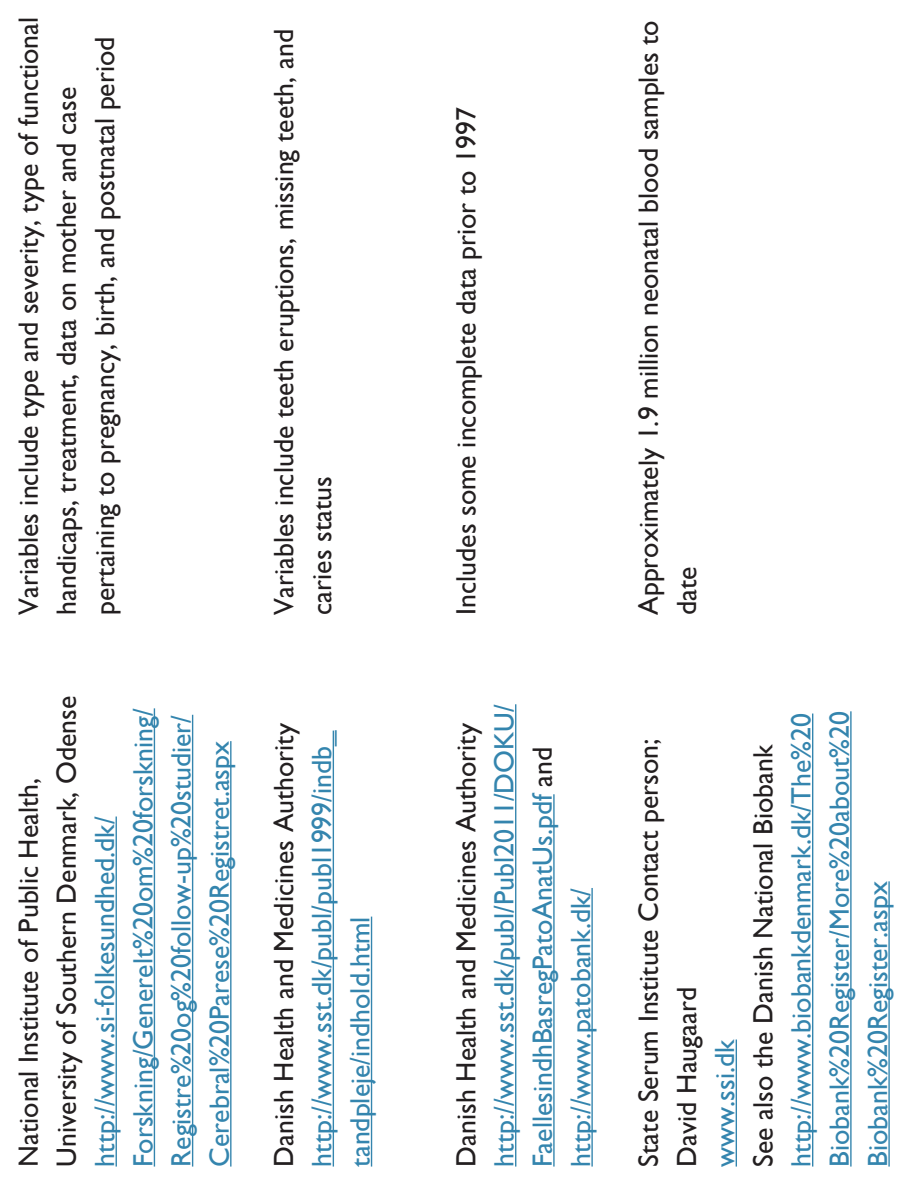

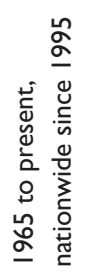
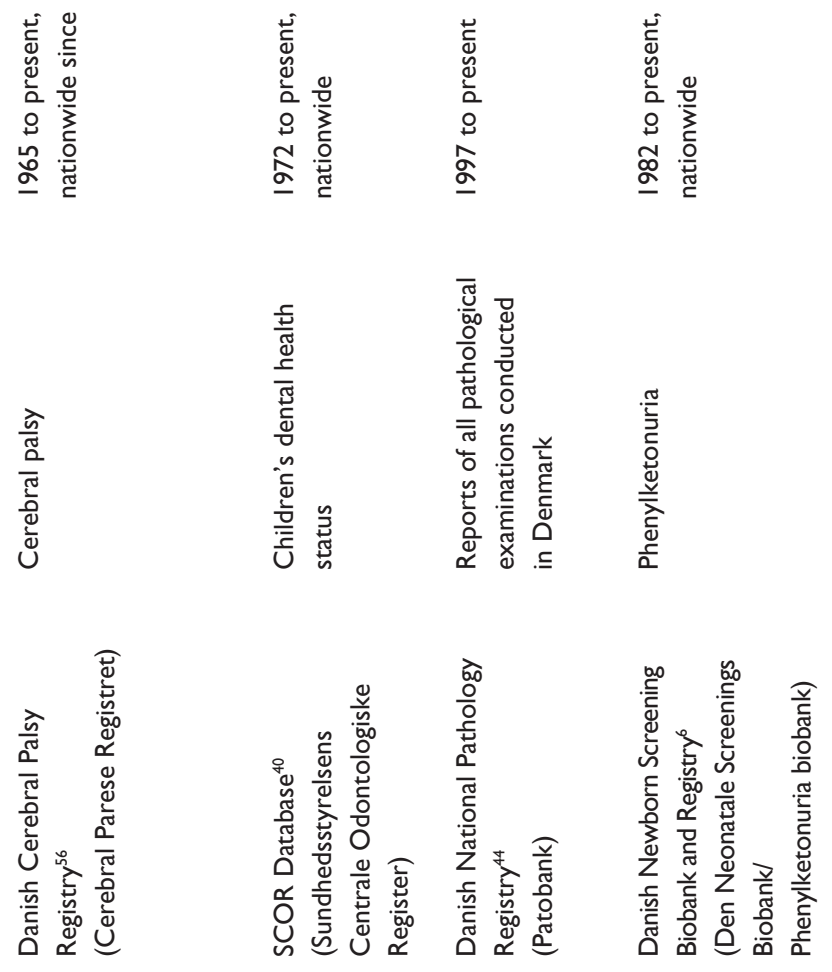
experts are consulted about the coding/registration practices for a particular genetic condition. For a number of genetic disorders, querying the DNRP should be supplemented with accessing data from the departments of clinical genetics or other specialized centers (see Table 2).

The National Pathology Registry ${ }^{44}$ (www.patobank. dk) is a registry of histological examinations reported by pathologists. Data have been collected since 1997. Variables include (but are not limited to) histological specimens, procedures, and diagnoses (primarily topography and morphology, but other features may also be registered). Diagnoses are coded using the International Systemized Nomenclature of Medicine. The National Pathology Registry is a potential source of data for conditions diagnosed by histopathological examination, such as cancers and genodermatoses.

The Civil Registration System is an administrative registry that provides up-to-date information on age, gender, region of residence, vital status, parent/child relationships, and other variables, including the CPR number. ${ }^{5,41}$ The Civil Registration System has data on every person who has legally resided in Denmark since April 1968. The CPR number enables linkage of data from multiple registries, and thereby the collection of data at the individual and familial levels, unambiguously and without double-counting. Data in the Civil Registration System is virtually complete, eg, vital status is updated electronically on a daily basis.

In addition to the previously mentioned data sources (ie, the Civil Registration System and the Danish Medical Birth Registry), church book archives are also potential sources for identifying relatives and pedigrees. Finally, Statistics Denmark (www.dst.dk), which includes StatBank Denmark (www.statbank.dk), contains descriptive statistical information on the Danish society, including data on household/ families and children.

\section{Danish research setting}

Access to Danish registry data and data linkage requires authorization by the Danish Data Protection Agency (Datatilsynet) and in some cases, additional authorization from the Danish Health and Medicines Authority, typically when medical charts are to be accessed, ${ }^{46}$ and/or authorization from the National Committee on Health Research Ethics (Den Nationale Videnskabsetiske Komité) if biological specimens are to be used or if living persons are to participate in clinical studies. The Danish privacy laws on the use of personal data are stipulated in The Act on the Processing of Personal Data (Act Number 429; May 31, 2000). ${ }^{47,48}$
As a general rule, the results of statistical analyses may be published or publicly released in an aggregated form such that individuals remain nonidentifiable. Otherwise, public release of any individual data (ie, data that can lead to identification of an individual) requires explicit consent from that person. For further information on Danish privacy laws and online application for authorization to access registry data, visit the Danish Data Protection Agency homepage ( www.datatilsynet.dk).

Once authorization for data access has been granted by the Danish Data Protection Agency, data can be obtained after approval and release by the individual registry administrators. For the national registries housed at the Danish State Serum Institute (Statens Serums Institut), an application for data release must be filed at the research service unit of this institute (Forskerservice, at http://www. ssi.dk/Sundhedsdataogit/Forskerservice.aspx).

Scientists in other European Union countries are subject to the same guidelines and procedures for data access as scientists in Denmark (described above). Release of registry data to non-European Union countries may require further evaluation by the Danish Data Protection Agency in order to ensure sufficient data security and handling in accordance with Danish law. Detailed information on the application procedure for data access for researchers outside Denmark can be found at the Danish Data Protection Agency homepage (http://www.datatilsynet.dk/erhverv/tredjelande/ overfoersel-til-tredjelande/).

\section{Conclusion}

There is a wealth of existing medical data sources on genetic diseases in Denmark. The ability to link and collect data at both the individual and familial levels allows for rapid identification of relevant study subjects/families and the collection of comprehensive medical histories spanning from time of birth to death. The Danish collection of medical registries is a valuable resource for genetic epidemiology and comparative effectiveness research, both in and outside of Denmark.

\section{Acknowledgments}

This study received funding from the Department of Clinical Epidemiology Research Foundation. Our sincere thanks are extended to the following people for their help in collecting information for this project: Jette Ørsted (Department of Clinical Genetics, Aarhus University Hospital), Sven Asger Sørensen (Institute for Cellular and Molecular Genetics, Panum Institute, Copenhagen University), Thomas Rosenberg (The National Eye Clinic, Kennedy 
Center, Copenhagen), Inge Bernstein (HNPCC-registry Clinical Research Center, Hvidovre Hospital), Hanne Buciek Hove (Department of Clinical Genetics, Rigshospitalet), Oluf Schiøtz (Department of Pediatrics, Aarhus University Hospital), Hanne Vebert Olesen (Department of Pediatrics, Aarhus University Hospital), Susanne Møller (Danish Breast Cancer Cooperative Group), Niels Jespersen (Department of Gastric Surgery, Hvidovre Hospital), Søs Marie Luise Bisgaard (Cellular and Molecular Medicine, Panum Institute, Copenhagen University), Marie Louise Mølgaard Binderup (Cellular and Molecular Medicine, Panum Institute, Copenhagen University), Charlotte Kvist Lautrup (Department of Clinical Epidemiology, Aarhus University Hospital), Allan Meldgaard Lund (Clinic for Rare Handicaps, Rigshospitalet), Ann Tabor (Center for Fetal Medicine and Pregnancy, Department of Obstetrics, Rigshospitalet), Mette Sommerlund (Department of Dermatology, Aarhus University Hospital), Anette Bygum (Department of Dermatology, Odense University Hospital), Stense Farholt (Centre for Rare Diseases and Department of Pediatrics, Aarhus University Hospital), Hans Gjørup (Centre for Oral Health in Rare Diseases, Aarhus University Hospital), Anne-Marie Gerdes (Department of Clinical Genetics, and the Clinic for Rare Handicaps, Rigshospitalet, Copenhagen), Karen Brøndum-Nielsen (Kennedy Center, Copenhagen), Michael B. Petersen (Department of Clinical Genetics, Aalborg University Hospital), Jette DaugaardJensen (Centre for Rare Oral Diseases, Odontologisk Videncenter, Copenhagen), Lotte Nylandsted Krogh (Department of Clinical Genetics, Odense University Hospital), Anders Bojesen (Department of Clinical Genetics, Vejle Hospital), Jens Michael Hertz (Department of Clinical Genetics, Odense University Hospital) and Camilla Daasnes (Data Protection Agency).

\section{Disclosure}

The authors declare no conflicts of interest in this work.

\section{References}

1. Frank L. Epidemiology. When an entire country is a cohort. Science. 2000;287(5462):2398-2399.

2. Frank L. Epidemiology. The epidemiologist's dream: Denmark. Science. 2003;301(5630):163.

3. Broeng-Nielsen B. Danish Family Studies of Medical Genetic Disorders 1927-1980: An Annotated Bibliography. Odense, Denmark: Danish Medical Research Council; 1982.

4. Health care in Denmark. Available from: http://www.sum.dk/Aktuelt/ Publikationer/Publikationer/UK_Healthcare_in_DK.aspx. Accessed May 1, 2013.

5. Pedersen CB, Gotzsche H, Moller JO, Mortensen PB. The Danish Civil Registration System. A cohort of eight million persons. Dan Med Bull. 2006;53(4):441-449.
6. Norgaard-Pedersen B, Hougaard DM. Storage policies and use of the Danish Newborn Screening Biobank. J Inherit Metab Dis. 2007;30(4):530-536.

7. Sørensen HT, Christensen T, Kjeldahl Schlosser H, Pedersen L. Use of Medical Databases in Clinical Epidemiology. New York, NY: Wiley and Sons; 2009.

8. Videbech P, Nielsen J. Electronic data processing in the Danish cytogenetic central register and EDP problems of registers in general. Clin Genet. 1979;15(2):137-146.

9. Ekelund CK, Petersen OB, Skibsted L, et al. First-trimester screening for trisomy 21 in Denmark: implications for detection and birth rates of trisomy 18 and trisomy 13. Ultrasound Obstet Gynecol. 2011;38(2):140-144.

10. Jorgensen KT, Rostgaard K, Bache I, et al. Autoimmune diseases in women with Turner's syndrome. Arthritis Rheum. 2010;62(3):658-666.

11. Bernstein IT, Lindorff-Larsen K, Timshel S, et al. Biomedical informatics as support to individual healthcare in hereditary colon cancer: the Danish HNPCC system. Hum Mutat. 2011;32(5):551-556.

12. Myrhoj T, Bernstein I, Bisgaard ML, et al. The establishment of an HNPCC register. Anticancer Res. 1994;14(4B):1647-1650.

13. Danish Breast Cancer Cooperative Group, 2012. Available from: http:// www.dbcg.dk/. Accessed May 1, 2013.

14. Burn J, Gerdes AM, Macrae F, et al. Long-term effect of aspirin on cancer risk in carriers of hereditary colorectal cancer: an analysis from the CAPP2 randomised controlled trial. Lancet. 2011;378(9809): 2081-2087.

15. Gjerstorff ML. The Danish Cancer Registry. Scand J Public Health. 2011;39(Suppl 7):42-45.

16. Storm HH, Michelsen EV, Clemmensen IH, Pihl J. The Danish Cancer Registry - history, content, quality and use. Dan Med Bull. 1997;44(5):535-539.

17. Jensen AR, Overgaard J, Storm HH. Validity of breast cancer in the Danish Cancer Registry. A study based on clinical records from one county in Denmark. Eur J Cancer Prev. 2002;11(4):359-364.

18. World Health Organization. WHO International Classification of Diseases ICD-10. Version 2010. Available from: http://apps.who.int/ classifications/icd10/browse/2010/en. Accessed May 1, 2013.

19. Winther J, Olsen JH, de Nully Brown P. Risk of nonocular cancer among retinoblastoma patients and their parents. A population-based study in Denmark, 1943-1984. Cancer. 1988;62(7):1458-1462.

20. Danish Society of Huntington Disease. Available from: http://huntingtons. dk/omlhc/LHCNyt/sidstenr.asp. Accessed May 1, 2013. Danish.

21. Fenger K, Sørensen SA. A computerised register for Huntington's chorea in Denmark. Clin Genet. 1986;29(5):460-461.

22. Jensen P, Fenger K, Bolwig TG, Sorensen SA. Crime in Huntington's disease: a study of registered offences among patients, relatives, and controls. J Neurol Neurosurg Psychiatry. 1998;65(4):467-471.

23. Orth M; European Huntington's Disease Network. Observing Huntington's disease: the European Huntington's Disease Network's Registry. J Neurol Neurosurg Psychiatry. 2011;82(12):1409-1412.

24. Danish Cystic Fibrosis Association. Available from: http://www.cff. $\mathrm{dk} /$ cfforeningen/downloads/defaultdownloads.html. Accessed May 1, 2013. Danish.

25. European Cystic Fibrosis Society. Annual reports. Available at: http:// ecfs.eu/projects/ecfs-patient-registry/annual-reports. Accessed May 1, 2013.

26. Nielsen $\mathrm{OH}$, Thomsen BL, Green A, Andersen PK, Hauge M, Schiøtz PO. Cystic fibrosis in Denmark 1945 to 1985. Acta Paediatr Scand. 1988;77(6):836-841.

27. Rosenberg T, Schwartz M. X-linked ocular albinism: prevalence and mutations - a national study. Eur J Hum Genet. 1998;6(6):570-577.

28. Haim M. Epidemiology of retinitis pigmentosa in Denmark. Acta Ophthalmol Scand Suppl. 2002;(233):1-34.

29. Christensen K, Knudsen LB. Registration of congenital malformations in Denmark. Dan Med Bull. 1998;45(1):91-94.

30. Larsen H, Nielsen GL, Bendsen J, Flint C, Olsen J, Sorensen HT. Predictive value and completeness of the registration of congenital 
abnormalities in three Danish population-based registries. Scand $J$ Public Health. 2003;31(1):12-16.

31. Zhu JL, Basso O, Hasle H, Winther JF, Olsen JH, Olsen J. Do parents of children with congenital malformations have a higher cancer risk? A nationwide study in Denmark. Br J Cancer. 2002;87(5):524-528.

32. Knudsen LB, Olsen J. The Danish Medical Birth Registry. Dan Med Bull. 1998;45(3):320-323.

33. Danish Society of Fetal Medicine. Available from: http://www.dfms. $\mathrm{dk} /$ foetodata.shtml. Accessed May 1, 2013.

34. Langtved Data A/S. Available from: http://www.langtved.dk/pages/dk/ genetics.html. Accessed May 1, 2013.

35. OMIM Home. Available at: http://www.ncbi.nlm.nih.gov/omim. Accessed May 29, 2012.

36. PASS Clinical Genetic. PASS Software. Available from: http:// www.pass-software.com/Producten/PASSClinicalGenetic/tabid/114/ language/en-US/Default.aspx. Accessed May 1, 2013.

37. Danish National Research Database. Available from: http://forskningsbasen.deff.dk/About.html. Accessed May 1, 2013.

38. Borberg A. Clinical and genetic investigations into tuberous sclerosis and Recklinghausen's neurofibromatosis; contribution to elucidation of interrelationship and eugenics of the syndromes. Acta Psychiatr Neurol Scand Suppl. 1951;71:1-239.

39. Sørensen SA, Mulvihill JJ, Nielsen A. Long-term follow-up of von Recklinghausen neurofibromatosis. Survival and malignant neoplasms. N Engl J Med. 1986;314(16):1010-1015.

40. SCOR Database. Available from: http://www.sst.dk/publ/publ1999/ indb_tandpleje/index.html. Accessed May 1, 2013.

41. Pedersen CB. The Danish Civil Registration System. Scand J Public Health. 2011;39(Supp1 7):22-25.

42. Nguyen-Nielsen M, Skovbo S, Svaneby D, Pedersen L, Fryzek J. The prevalence of X-linked hypohidrotic ectodermal dysplasia (XLHED) in Denmark, 1995-2010. Eur J Med Genet. February 14, 2013. Published June 1, 2013.

43. Lynge E, Sandegaard JL, Rebolj M. The Danish National Patient Register. Scand J Public Health. 2011;39(Suppl 7):3-33.

44. Erichsen R, Lash TL, Hamilton-Dutoit SJ, Bjerregaard B, Vyberg M, Pedersen L. Existing data sources for clinical epidemiology: the Danish
National Pathology Registry and Data Bank. Clin Epidemiol. 2010;2:51-56.

45. Ehrenstein V, Antonsen S, Pedersen L. Existing data sources for clinical epidemiology: Aarhus University Prescription Database. Clin Epidemiol. 2010;2:273-279.

46. Danish Health and Medicines Authority. Access to Patient Medical Charts. Available from: http://www.sst.dk/Tilsyn\%20og\%20patientsikkerhed/Patientjournaloplysninger.aspx. Accessed February 28, 2013.

47. Thygesen LC, Daasnes C, Thaulow I, Bronnum-Hansen H. Introduction to Danish (nationwide) registers on health and social issues: structure, access, legislation, and archiving. Scand J Public Health. 2011; 39(Supp1 7):12-16.

48. Danish Data Protection Agency. Available from: http://www.datatilsynet. $\mathrm{dk} /$ fortegnelsen/soeg-i-fortegnelsen/. Accessed May 1, 2013.

49. Welcome to the Nordic Database for Rare Diseases. Available from: https://raredis.eu/. Accessed May 1, 2013.

50. Haim M, Holm NV, Rosenberg T. A population survey of retinitis pigmentosa and allied disorders in Denmark. Completeness of registration and quality of data. Acta Ophthalmol (Copenh). 1992;70(2):165-177.

51. With TK. Hereditary hepatic prophyrias. Gene penetration, drug sensitivity and subdivision in the light of systematic family studies. Acta Med Scand. 1969;186(1-2):117-124.

52. Christensen SE, Nissen PH, Vestergaard P, et al. Plasma 25-hydroxyvitamin D, 1,25-dihydroxyvitamin D, and parathyroid hormone in familial hypocalciuric hypercalcemia and primary hyperparathyroidism. Eur $J$ Endocrinol. 2008;159(6):719-727.

53. Christensen SE, Nissen PH, Vestergaard P, et al. Skeletal consequences of familial hypocalciuric hypercalcaemia vs primary hyperparathyroidism. Clin Endocrinol (Oxf). 2009;71(6):798-807.

54. Lexner MO, Bardow A, Hertz JM, Nielsen LA, Kreiborg S. Anomalies of tooth formation in hypohidrotic ectodermal dysplasia. Int J Paediatr Dent. 2007;17(1):10-18.

55. Skytthe A, Kyvik K, Holm NV, Vaupel JW, Christensen K. The Danish Twin Registry: 127 birth cohorts of twins. Twin Res. 2002;5(5): 352-357.

56. Topp M, Langhoff-Roos J, Uldall P. Validation of a cerebral palsy register. J Clin Epidemiol. 1997;50(9):1017-1023.
Clinical Epidemiology

\section{Publish your work in this journal}

Clinical Epidemiology is an international, peer-reviewed, open access journal focusing on disease and drug epidemiology, identification of risk factors and screening procedures to develop optimal preventative initiatives and programs. Specific topics include: diagnosis, prognosis, treatment, screening, prevention, risk factor modification, systematic

\section{Dovepress}

reviews, risk \& safety of medical interventions, epidemiology \& biostatical methods, evaluation of guidelines, translational medicine, health policies \& economic evaluations. The manuscript management system is completely online and includes a very quick and fair peer-review system, which is all easy to use. 